\title{
Electrically actuated valves for gas compression installations located in potentially explosive atmospheres
}

\author{
Cristian Nechifor ${ }^{1}$, Claudia Borzea ${ }^{1^{*}}$, Iulian Vlăducă $^{1}$, Ion Mălăel ${ }^{1}$, and Filip Niculescu ${ }^{1}$ \\ ${ }^{1}$ Romanian Research and Development Institute for Gas Turbines COMOTI, 220D Iuliu Maniu Blvd., \\ 061126 Bucharest, Romania
}

\begin{abstract}
Using electric energy in a potentially explosive atmosphere raises several problems that must be solved when designing, manufacturing and during the operation of electric equipment. Their approach requires special attention, considering the multiple technical, economical and labour safety aspects. The ingress protection for the electrical part of the valves is ensured by the capsulation assembly, comprising the protection measures applied for preventing the ignition of the surrounding atmosphere. The labyrinth seal through which the gas flow passes is designed so as to confine a potential ignition inside actuator's flameproof enclosure. Numerical simulations were conducted for determining the combustion behaviour and the optimum width and geometry of the labyrinth canals.
\end{abstract}

\section{Introduction}

Rotary bladed machines such as screw compressors are industrial assemblies in which valves driven by electric motors are used, being mounted at least on the inlet and outlet pipes. The compressor unit is placed on a skid together with the driving electric motor and with the execution equipment for the command system, lubrication, heating/cooling oil and gas systems, as well as with the measuring system. [1]

Compressed gases are usually chemically aggressive gases, with high content of sulphures, hidrocarbons, etc. The evolution of gas-air mixtures explosion depends on how the flame propagates over time and space. In the literature, there are several studies regarding the mechanisms of flame propagation. The mechanism accepted by the worldwide researchers is based on heat transfer by radiation, conduction and convection, but also on the heterogeneous reaction and production of volatile components [2-5].

The paper presents the design of an electrically actuated valve in 'Ex d' flameproof construction, for use in European hazardous gaseous Zones 1 and 2 [6]. Numerical simulations can provide a wide range of efficient data regarding flame propagation, to estimate the results to be expected before making experimental studies which can be very expensive and time consuming [7,8]. Our study also considers the numerical solution for an optimal valve design in order to avoid flame propagation in a flammable environment.

\footnotetext{
* Corresponding author: claudia.borzea@comoti.ro
} 
Actuators are the interface between electronic signal processing and the actual process (mechanical motion), converting low-power signals that convey the positioning information into operating signals of an adequate energy level for process control. [9]

The jointing of the capsulation is realised by means of gaps with precise geometrical shapes and dimensions. These gaps have the purpose of cooling the flame and the secondary products resulted from an internal explosion, due to the heat absorption by flanges material and by adiabatic expansion. Thus cooled, burnt gases and metal particles resulted and heated during the explosion are not capable of igniting the potentially explosive gas mix from the surrounding atmosphere, when exiting the capsulation. [10]

\section{Valve design and electric actuation}

The valve will have an ingress protection factor of at least IP 67, which means maximum protection against dust particles and waterproof protection for immersion up to 1 meter, for 30 minutes. The electric components are classified within Group IIB, with T4 temperature class for hot surfaces $\left(\max .135^{\circ} \mathrm{C}\right)$. The marking of the valve's electrical actuation will be: Ex II 2G d IIB T4.

The assembly of valve actuated by electric motor comprises several subassemblies and parts, all of them having the role of contributing to the correct operation. Figure 1 shows the $3 \mathrm{D}$ CAD model of the valve with its main components.

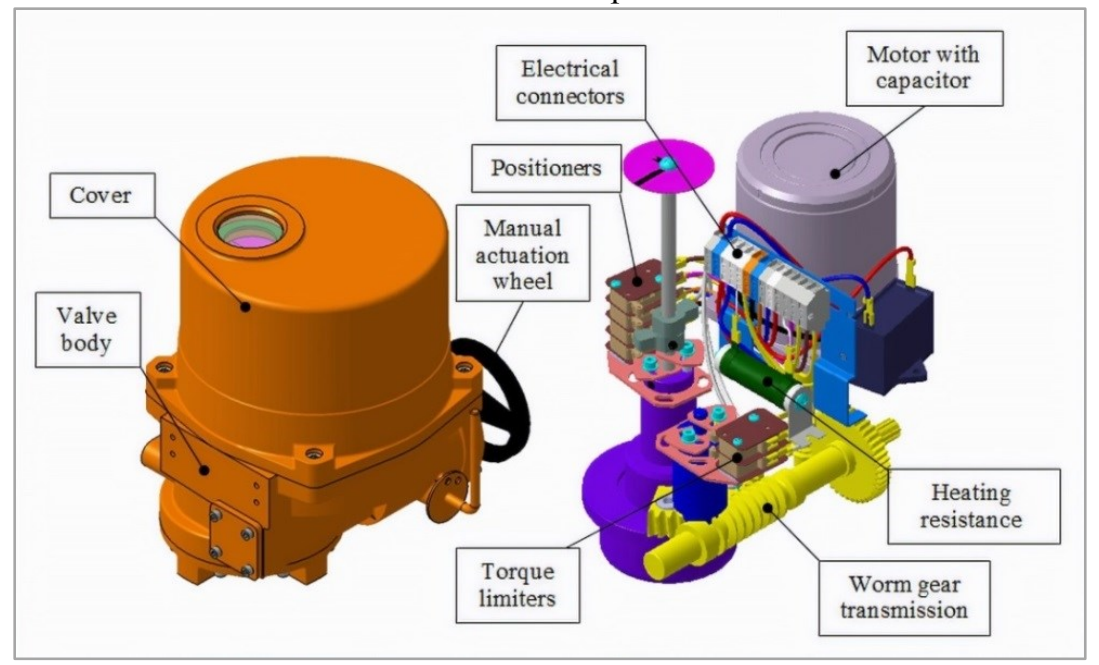

Fig. 1. Electric valve design elements

The maximum torque considered for this type of valve is $150 \mathrm{Nm}$, for which it was chosen a driving motor of $40 \mathrm{~W}$. Besides this valve, two other typo-dimensions were proposed, of $50 \mathrm{Nm}$ and $270 \mathrm{Nm}$, with motors of $25 \mathrm{~W}$ and respectively $90 \mathrm{~W}$.

The electronic cabinets ensure the command, control and monitoring of the compression installations and of the electrically actuated valves, and are situated within a short range from the skid, usually in a control room placed in an unclassified zone (non-hazardous). Before reaching the cabinets, the signal cables pass through an intermediary junction box, equipped with isolation amplifiers and terminal blocks. The cables from the field enter the box through Ex cable glands.

The Ex stainless steel enclosure with hinged lid ensures extremely good protection in harsh and aggressive environments. The lid takes the form of a door, and is secured by means of an internal hinge. The door, which is equipped with a double ward lock, allows 
quick and easy opening and closing of the enclosure at any time. The silicone lid seal used allows a service-temperature (with ATEX/IECEX certificate) ranging from $-55^{\circ} \mathrm{C}$ to $+135^{\circ} \mathrm{C}$. The Ex IGS (Integrated Gas System) enclosure provides a standard ingress protection degree of IP 66.

Isolation amplifiers are a form of differential amplifiers enabling to measure small signals in the presence of a high common mode voltage by providing electrical isolation and an electrical safety barrier. Their role is to protect data acquisition components from common mode voltages (potential differences between instrument ground and signal ground). Safety barriers make use of Zener diodes protected with resistors or fuses and are considered not to be damageable if at least three diodes are included for 'Ex ia' electrical circuits and at least two diodes for 'Ex ib' circuits. The safety barriers limit the voltage that passes through the circuit by means of diodes, and the current by using resistors, thus ensuring the intrinsic protection of the circuit [11]. A 3D CAD (Computer Aided Design) model of the junction box was realised in Solid Edge ST9 and is presented in Figure 2a).
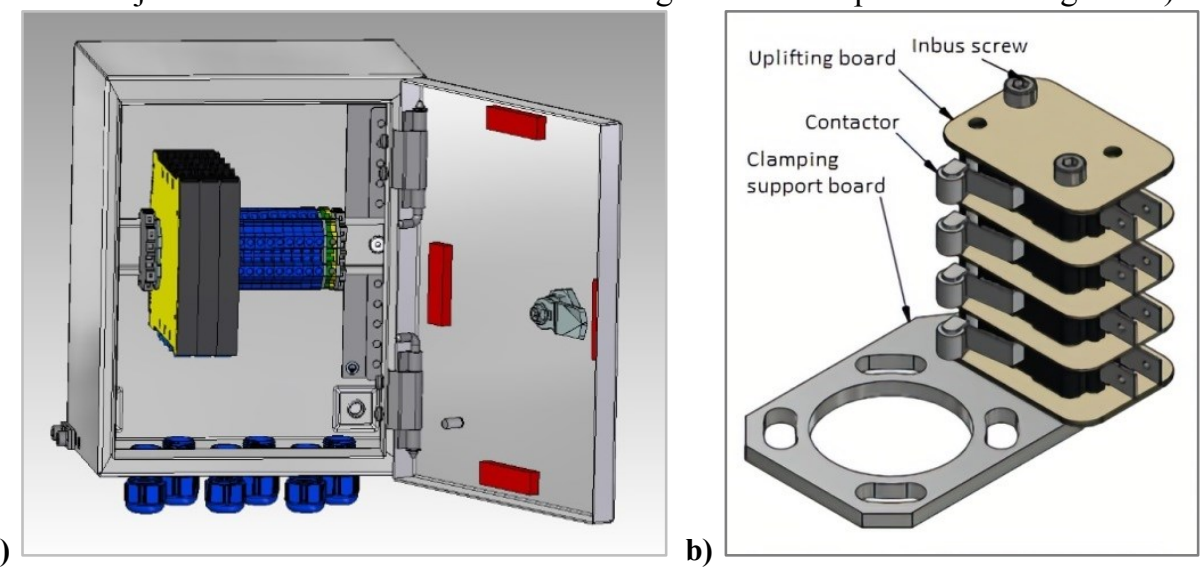

Fig. 2. a) Valve junction box, and b) Mechanical stroke limiter designed for the electric valve

The elementary part that drives the valve is represented by the actuator (electric motor). The role of the actuator is to transmit enough mechanical energy to drive the valve's shaft, so as to produce an effect upon the fluid (gas) that passes through. The motor is coupled with flange, being situated outside the valve's body in the flameproof capsulation ('Ex d'), along with the other command and control elements. The actuation elements used in explosive environments require special attention, since an improper operation may lead to disastrous events.

Asynchronous motors are the most used type of electrical actuation, due to their high dynamic load capacity, high start-up capacity, simple construction and robustness. Singlephase motors were considered the best solution for driving the valves, since we have a low power application, which does not require three-phase motors.

The mechanical stroke limiter with lever and reel which was designed for the valve (Figure $2 \mathrm{~b}$ above) is used to indicate the open, close, or intermediate positions of the valve. After a technical and economic research on several type of limiters (such as mechanical, optical, infrared, acoustic, capacitive, inductive, etc.), we have chosen a mechanical limiter to be the optimum solution. The factors considered were that it can operate in any environment, having high accuracy and insignificant power consumption. The stroke limiters transmit a confirmation signal to a PLC (Programmable Logic Controller), allowing the SCADA (Supervisory Control and Data Acquisition) system to acquire information about the position of the valve. For rougher exploitation applications, proximity limiters can be used, which serve the same purpose as mechanical ones. 


\section{Labyrinth seal gap geometry for flameproof protection}

Regarding the electrical actuation, the valve is able to operate in Zone 1. Therefore, its capsulation cannot contain a magnesium percentage of over $7.5 \%$. The material chosen for the capsulation was aluminium A380, with a maximum percentage of magnesium of $0.1 \%$. Aluminium alloys are used in oil \& gas industry due to their resistance to corrosion and for not producing sparks by accidental hits. They also present a very good conductivity, allowing the dissipation of thermal energy and of electrostatic charging within a short time.

According to theory, the main characteristic dimensions of 'Ex d' flameproof capsulation are volume $(V)$, width $(L)$ and gap $(i) . V$ is the free volume resulted after the electrical equipment has been placed in the enclosure, $L$ is the width of the jointing without holes, and $i$ is the gap between the cover and actuator's body. Relying on [12], depending on volume $V$ and width $L$, we extract the maximum gap $i$ allowed at jointing the flameproof enclosure, which can be closed hermetically with a seal, yet without this one partaking in the flameproof properties of the capsulation.

Figure 3 below presents the 2D assembly drawing of the electrical actuation, focusing on the radial labyrinth jointing between the actuation cover and the enclosure, and also on the separation zone between the electrical and non-electrical areas.

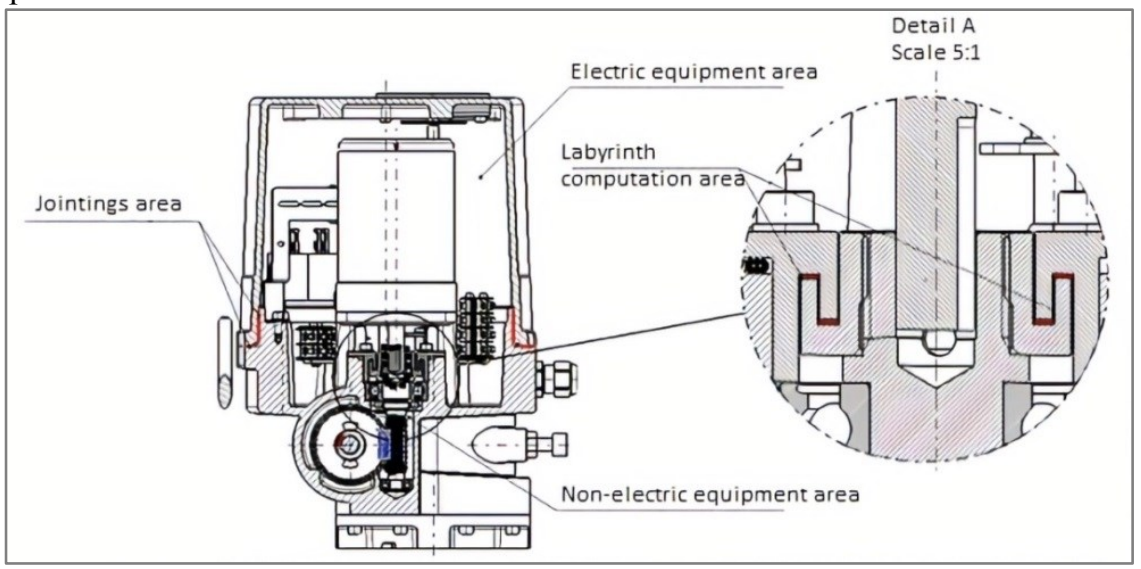

Fig. 3. Valve 2D assembly drawing with labyrinth seal detail

In order to determine the maximum gap allowed at jointing, the free inner volume of the capsulation was determined by subtracting the volumes of the mounted components. This was realised using the 3D modelling software CATIA V5R23, in which the assembly was designed. The free volume $\mathrm{V} \cong 4690 \mathrm{~cm}^{3}$ determined is shown in Figure 4 .
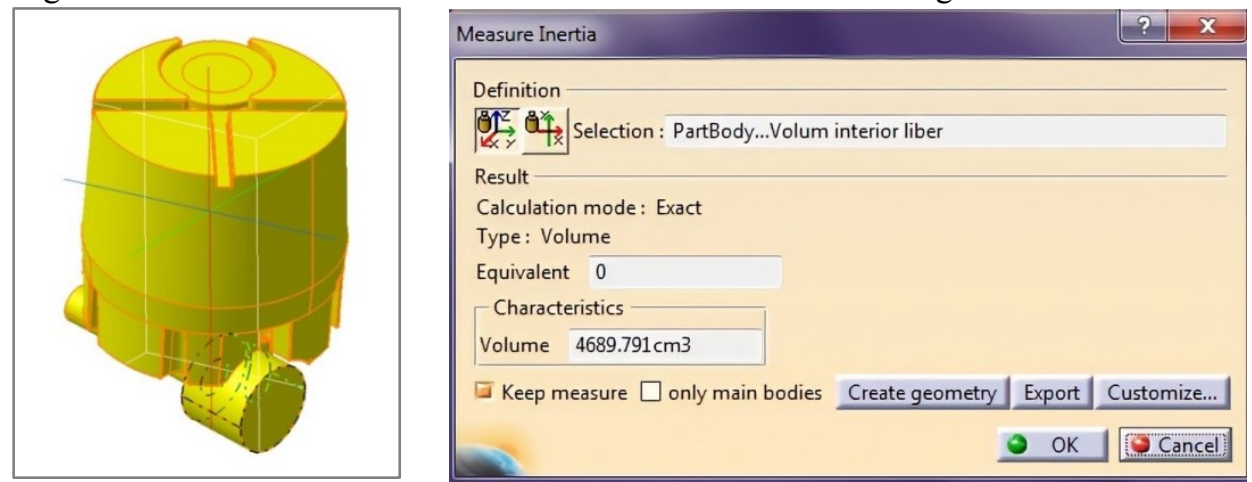

Fig. 4. Free volume determination using CATIA V5R23 3D modelling software 
According to [12], for a minimum width of $12.5 \mathrm{~mm}$, we will have, for a volume larger than $2000 \mathrm{~cm}^{3}$, an admissible gap of $0.15 \mathrm{~mm}$ for the equipment in Group IIB, intended for applications specific to oil and gas area (including Group IIA). Group IIC belongs to gases type hydrogen and acetylene, which do not make the object of this paper. Group I is also not addressed in this paper, as it refers to firedamp (mining zone).

Considering that, after a potential explosion, the gap can enlarge due to cover dilatation, structural strength computations are necessary for assessing the deformation of actuator's cover. Strength computations are a reliable way to verify the correct dimensioning of the cover, so that during a deflagration, the maximum gap not to exceed $0.15 \mathrm{~mm}$. The pressure in the expansion chamber is much below the critical pressure, namely:

$$
p_{c r}=p_{0} \beta_{c r} \Rightarrow p_{c r}=10.92 \mathrm{bar}
$$

where: $p_{c r}$ - critical pressure; $p_{0}$ - detonation pressure $\left(p_{0}=20 \mathrm{bar}\right) ; \beta_{c r}$ - critical pressure ratio $\left(\beta_{c r}=0.546\right.$, for gases resulted from detonation).

If we consider that initially the pressure is the atmospheric one, during the stages of gases passing through minimum sections, the maximum gas flow that can pass through section $A_{\min }$ is given by the following relation [13]:

$$
\dot{m}_{\max }=-\frac{d m}{d \tau}=A_{\min } \frac{P}{\sqrt{R T}} \sqrt{\gamma\left(\frac{2}{\gamma+1}\right)^{\frac{\gamma+1}{\gamma-1}}}
$$

where: $\dot{m}_{\max }$ - maximum mass flow; $d m$ - infinitesimal mass; $d \tau$ - infinitesimal time; $A_{\text {min }}$ - minimum passing section; $P$ - upstream pressure; $T$ - upstream temperature; $R$ - gas constant in detonation process (variable); $\gamma$ - polytropic coefficient of gases in detonation process (variable).

If the gas is forced to pass through a narrow tube, we will have a lamination process, or Joule-Thomson process, in which temperature modification occurs due to internal mechanical work, produced by gas molecules during the expansion process. This process occurs at constant enthalpy, because there is no heat exchange with the surrounding environment. The lamination process is irreversible, and bringing the gas back to its initial state requires energy consumption [14].

\section{Numerical simulations}

Due to the complex process of gas transformation by lamination, and taking into account that a complex iterative computation is required, a numerical CFD (Computational Fluid Dynamics) analysis of the gas flow through the labyrinth has been conducted. Using the 3D CAD model of an anti-explosion valve, a 2.5D computational domain has been defined, with a small width (Figure 5a)). The numerical study was performed considering two cases with different dimensions of the labyrinth gap (Figures 5b) and 5c)).

a)

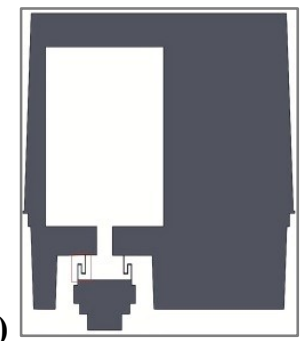

b)

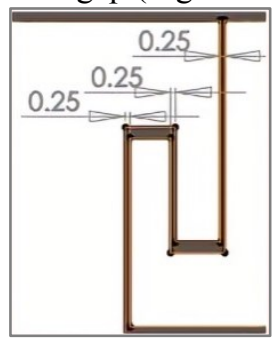

c)

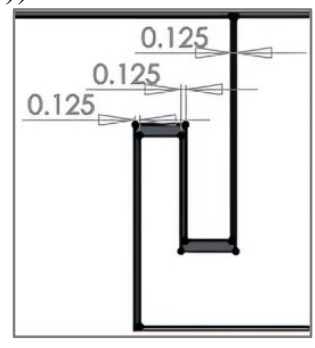

Fig. 5. a) Simplified 2.5D valve model; Labyrinth sealing gap: b) Case 1 and c) Case 2 
Using ANSYS CFX, a two-equation turbulence model $(\mathrm{k}-\varepsilon)$ was used for investigating the flame propagation in a closed domain. In order to obtain a good simulation quality with more reliable solutions, an optimal choice was made for the meshes in terms of orthogonality, expansion ratio and cell aspect ratio. An ignition was simulated at $(0.1,0,0)$ location, by declaring a spark with total source energy of $100 \mathrm{~W}$. A 2.5D CFD analysis was conducted for the anti-explosion valve. A comparative study between the two labyrinth sealing gaps was conducted, to investigate the flame propagation. The subsequent figures show the temperature evolution at different simulation time steps, for both cases discussed.

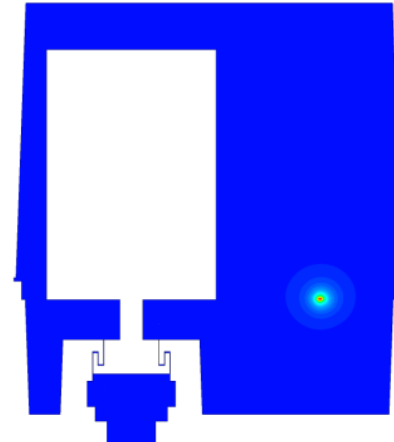

a) Case 1 , at $\Delta \mathrm{t}=0.1 \mathrm{~s}$

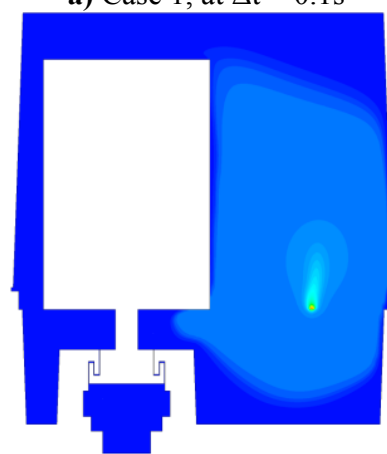

a') Case 1 , at $\Delta \mathrm{t}=0.2 \mathrm{~s}$

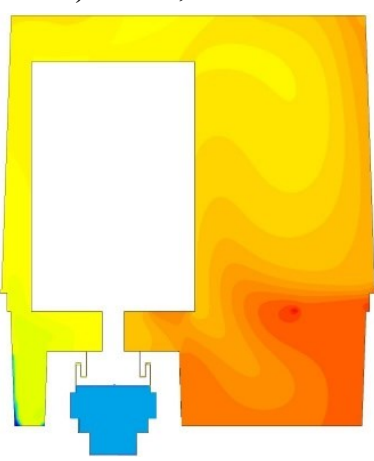

a') Case 1 , at $\Delta \mathrm{t}=0.3 \mathrm{~s}$

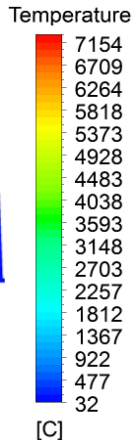

$[\mathrm{C}]$
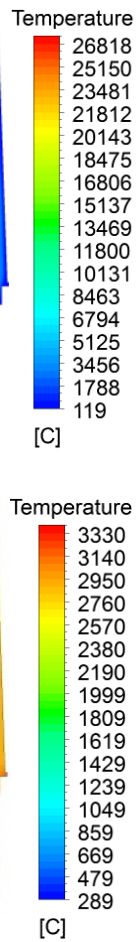

[C]

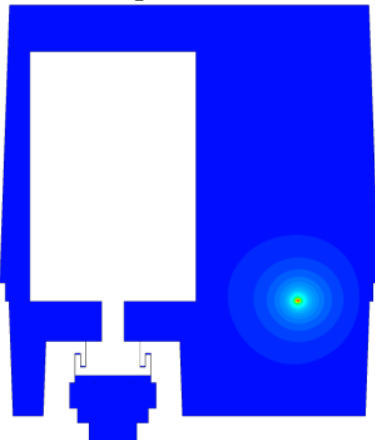

b) Case 2, at $\Delta \mathrm{t}=0.1 \mathrm{~s}$

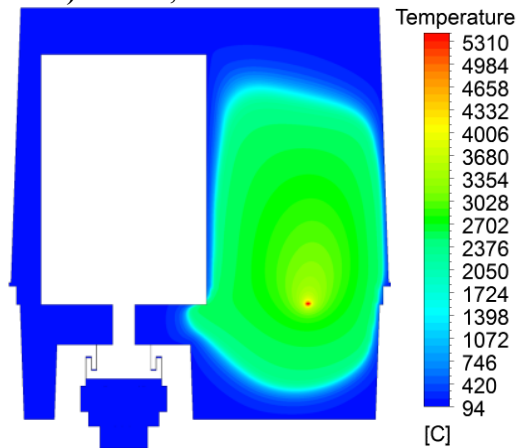

b') Case 2, at $\Delta \mathrm{t}=0.2 \mathrm{~s}$

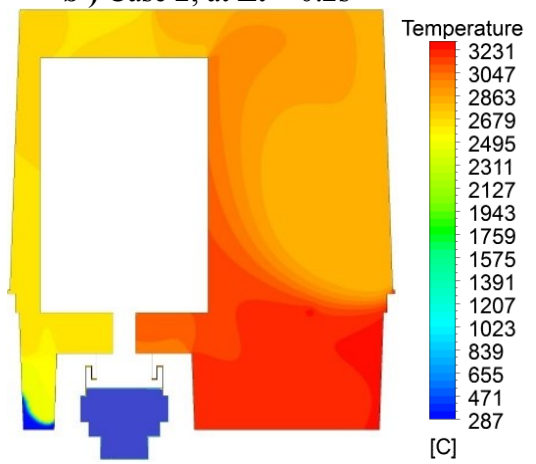

b") Case 2, at $\Delta \mathrm{t}=0.3 \mathrm{~s}$

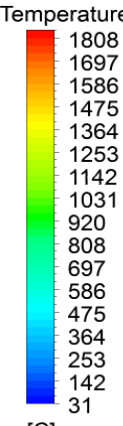

[C]
Fig. 6. Temperature variation for Case $1(0.25 \mathrm{~mm})$ and Case $2(0.125 \mathrm{~mm})$ at different time steps

The simulation shows that the labyrinth seal manages to confine the flame during the whole explosion time. The gas temperature in the lower chamber, after the exit from the labyrinth, is about $600^{\circ} \mathrm{C}$ in Case $1(0.25 \mathrm{~mm}$ gap) and in Case $2(0.125 \mathrm{~mm}$ gap $)$, the temperature decreases to about $300^{\circ} \mathrm{C}$, which is under the ignition temperature of ethylene, of $450^{\circ} \mathrm{C}$. Halving gap width results in a decrease of the explosion temperature with $\sim 50 \%$. 


\section{Conclusions}

The paper presents the design of an electrically actuated valve in flameproof construction 'Ex d'. The equipment is identified as part of Group II gases, 2G category (also allowing the operation in Zone 1). Computations have been done regarding the formation of an explosive atmosphere in two cases of labyrinth gap, inside the enclosure of the designed electric actuator. We assessed its ability to withstand a combustion event, either by totally confining the gases, or by cooling the gases down to a temperature under the ignition limit of the surrounding explosive atmosphere.

The simulation shows that both the $0.25 \mathrm{~mm}$ and $0.125 \mathrm{~mm}$ labyrinth seal gaps are able to confine the flame inside the capsulation, but the second case is better due to temperature decrease under the limit of gas ignition. However, more accurate computations are required. Future work will consider a 3D simulation, since significant errors can occur in a $2.5 \mathrm{D}$ simplified geometry with a certain small width declared. If the explosion is confined, a full scale destructive test will be performed to confirm the numerical analysis.

Future research will also consider implementing an innovative solution with optical encoder for determining the opening angle of the valve, and systems integrating auxiliary contacts, with optical position sensors, which can provide information regarding valve's opening percentage.

The research work presented herein was funded by Competitiveness Operational Program 2014-2020, Priority Axis 1 - Research, Technological Development and Innovation in Support of Economic Competitiveness and Business Development, project acronym EPAVREDI, contract no.: 132 / 23.09.2016, carried out with the support of Romanian Ministry of European Funds.

\section{References}

1. A. Mitru, C. Dumitru, R. Iorga, International Symposium on Occupational Health and Safety - SESAM 2015, 307-315 (2015).

2. H. Pitsch, E. Reismeier, N. Peters, Combust. Sci. Tech., 158, 389-406 (2000).

3. D. Lignell, J. Chen, P. Smith, T. Lu, C. Law, 5th U.S. Combustion Meeting (San Diego, 2007).

4. T. Løvås, N. Malik, F. Mauss, Combust. Sci. Tech., 182 (11-12), 1945-1960 (2010).

5. W. Wang, B. Rogg, Reduced kinetic mechanisms for applications in combustion systems, 76-101 (Springer, Berlin, Heidelberg, 1993).

6. Directive 2014/34/EU (2014).

7. S. Sun, M. Wang, Y. Qiu, K. Gao, Energy, 178, 186-194 (2019).

8. Y. Chen, T. Yao, Q. Wang, K. H. Luo, Fuel, 255, 115734 (2019).

9. R. Heinz, R. Schenk, Electric Actuators, in: K. Reif (eds) Automotive Mechatronics, 290-301 (Springer Vieweg, Wiesbaden, 2015).

10. M. Magyari, I. L. Moldovan, D. Fotău, M. D. Rad, D. Sălășan, Cerințe de securitate pentru echipamentele electrice cu tip de protecţie capsulare antideflagrantă din arii periculoase, altele decât minele grizutoase (INSEMEX, 2019).

11. M. Darie, C. S. Burian, T. A. Csaszar, C. I. Colda, D. N. Grecea, A. Andriş, G. Pupăzan, Cerințe de securitate pentru echipamentele electrice cu tip de protecție securitate intrinsecă din arii periculoase, altele decât minele grizutoase (INSEMEX, 2019).

12. Standard SR EN 60079-1 (2015).

13. V. Radcenko, N. Alexandrescu, E. Ionescu, M. Ionescu, Calculul şi proiectarea elementelor şi schemelor de automatizare (Editura Tehnică, 1985).

14. S. Anghel, Fenomene termice (Editura Universităţii din Piteşti, 2017). 